\title{
MANEJO DE PRAGAS E DOENÇAS NA PRODUÇÃO INTEGRADA E CONVENCIONAL DE PÊSSEGOS 1
}

\author{
CASIANE SALETE TIBOLA ${ }^{2}$, JOSÉ CARLOS FACHINELLO ${ }^{3}$, ANDERSON DIONEI GRÜTZMACHER ${ }^{4}$, \\ LUCIANO PICOLOTTO 5 , LEANDRO KRÜGER ${ }^{6}$
}

\begin{abstract}
RESUMO - A Produção Integrada de Pêssego (PIP) está sendo desenvolvida na região de Pelotas-RS, desde o ano de 1999, com o objetivo de avaliar, agronomicamente, o sistema de Produção Integrada (PI) comparado com o sistema de Produção Convencional (PC), em pomar de pessegueiro cv. Diamante. Foram analisados os dados de cinco safras (1999-2003), onde as avaliações compreenderam danos causados por pragas: grafolita, moscadas-frutas, gorgulho e cochonilha; ocorrência de doenças: podridão-parda, bacteriose, sarna e outras doenças; e número de aplicações de agrotóxicos. Os danos por grafolita foram de $1,11 \%$ e de $1,69 \%$, para os sistemas PI e PC, respectivamente. Os danos decorrentes do ataque pelo gorgulho do milho foram de $2,12 \%$ na PI e $0,86 \%$ na PC. No sistema PI, o percentual de frutas com podridão-parda foi de $26,27 \%$ e na PC foi de $30,55 \%$, sendo a maior causa das perdas nos pomares. A ocorrência de sarna foi muito elevada na área com PC, no ano de 2003 , atingindo $33,82 \%$ dos frutos analisados. O número de tratamentos fitossanitários foi maior na PC, em 1999 e 2000 e, posteriormente, houve similaridade nos tratamentos efetuados nos dois sistemas PI e PC. A avaliação conjunta dos resultados demonstra uma superação do sistema PI, quando comparado com o sistema PC, nos parâmetros analisados, indicando que é possível conduzir os pomares de pessegueiro de acordo com as Normas de Produção Integrada de Pêssego. Termos para indexação: monitoramento, agrotóxicos, selo de conformidade, rastreabilidade
\end{abstract}

\section{HANDLING OF PESTS AND DISEASES IN INTEGRATED AND CONVENTIONAL PRODUCTION OF PEACH}

ABSTRACT - The Integrated Production of Peach (IPP) is being developed in Pelotas, Rio Grande do Sul, since the year 1999, with the objective to evaluate agronomically the Integrated Production (IP) system compared with Conventional Production (CP), in peach orchard 'Diamante'. The data of five harvests periods (1999-2003) and the evaluations were: damages for pests: oriental fruit moth, fruit flies, maize weevil and white peach scale; diseases: rotting, bacteria, scab and others; number of chemicals applications. The damages for oriental fruit moth were $1.11 \%$ and $1.69 \%$, in IP and CP system, respectively. The damages of maize's weevil, was $2.12 \%$ in IP and $0.86 \%$ in the CP. In the IP system, the percentage of fruits with rooting was $26.27 \%$ and in the $\mathrm{CP}$ it was $30.55 \%$, being the biggest cause of the losses in the orchards. The scab occurrence had risen in the CP, in 2003 , reaching $33.82 \%$ of the fruits analyzed. The number of chemicals treatments was bigger in the CP, in 1999 and 2000, later on there were similarity in the treatments applied in both systems, IP and CP. The evaluation of the results showed that the IP system was superior to the CP system, when those parameters were compared, indicating that it is possible to handle the peach orchards according to the Integrated Production.

Index terms: monitoring, chemicals, stamp of conformity, traceability

\section{INTRODUÇÃO}

As atuais exigências de mercado fundamentam-se, cada vez mais, na segurança alimentar dos produtos agrícolas que são comercializados. Por outro lado, o conceito de qualidade tem evoluído, além das características próprias dos produtos, também é exigido que estes cumpram normas de qualidade preestabelecidas, sejam saudáveis, considerem a preservação do meio ambiente na sua obtenção e a segurança do produtor, e tudo deverá ser certificado por uma empresa que ofereça garantias (Gonzalez-Moro, 2003).

Em 1976, na Suíça, discutiram-se as relações entre manejo de fruteiras e a proteção integrada das plantas, evidenciando-se a necessidade da adoção de um sistema que atendesse às peculiaridades do agroecossistema, de forma a utilizar associações harmônicas, relacionadas com as práticas de produção. Neste contexto, incluíram-se o manejo integrado e a proteção das plantas, fatores fundamentais para obtenção de produtos de qualidade, com sustentabilidade ambiental (Sanhueza et al., 2003). Em 1993, foram publicados pela IOBC (International Organization for Biological and Integrated Control of Noxions Animals and Plants) os princípios e normas técnicas pertinentes, que são comumente utilizados e aceitos como base para diretrizes específicas para cada cultura.

A adoção do sistema Produção Integrada de Frutas (PIF) evoluiu em curto espaço de tempo e, atualmente, é amplamente empregado em vários países, apresentando resultados positivos, tornando-se, rapidamente, um pré-requisito na comercialização de frutas (Sanhueza, 2000). Na Europa, na década de 80, Alemanha, Bélgica, Suíça,
Espanha e França foram os precursores da implementação da PIF nos pomares (Sanhueza et al., 2003).

No Brasil, em 1997, iniciou-se a implementação do projeto PIF para macieira e, em 1999, foi ampliado para frutas de caroço, uva de mesa e manga, contemplando atualmente 14 espécies frutíferas. O projeto teve como objetivo desenvolver as bases técnicas, econômicas e operacionais, que permitam a incorporação do Brasil ao sistema de produção integrada de frutas, para obter produtos com qualidade, melhorando a competitividade e a rentabilidade da fruticultura (Andrigueto \& Kososki, 2002).

O sistema 'Modelo de Avaliação da Conformidade da PIF', oficializado em setembro de 2002, estabelece a regulamentação da PIF, através de auditorias nas áreas produtivas, podendo receber um selo de conformidade, atestando a qualidade, com a garantia de que todos os procedimentos foram realizados sob o controle de um organismo certificador credenciado pelo Instituto Nacional de Metrologia (Inmetro, 2004).

As pragas são consideradas um dos principais fatores limitantes à exploração econômica do pessegueiro, destacando-se a mariposa oriental (Grapholita molesta Busk) e a mosca-das-frutas (Anastrepha fraterculus Wied). Além dessas, em algumas regiões, tem sido observada a presença de pragas secundárias, como cochonilhas, pulgões, gorgulhos e ácaros. A ocorrência desses insetos, entretanto, geralmente está associada a desequilíbrios provocados pelo uso indevido de inseticidas, de amplo espectro, visando ao controle das pragas primárias (Botton et al., 2003).

A ocorrência de doenças, principalmente a podridão-parda

\footnotetext{
(Trabalho 108/2004). Recebido: 17/04/2004. Aceito para publicação: 05/08/2005. Projeto realizado com apoio financeiro do MAPA/CNPq e FAPERGS.

${ }^{2}$ Eng. Agr. ${ }^{\text {a } D r . ~}{ }^{\text {a }}$ Fruticultura de Clima Temperado - FAEM/UFPel. Rua: Félix da Cunha, 814/101. CEP: 96010-000. Pelotas-RS. E-mail: casiane@ufpel.tche.br .

${ }^{3}$ Eng. Agr. Professor Titular do Departamento de Fitotecnia - FAEM/UFPel. Cx. Postal: 354, CEP: 96010-900. Pelotas - RS. E-mail: jfachi@ufpel.tche.br.

${ }^{4}$ Eng. Agr. Professor Adjunto do Departamento de Fitossanidade - FAEM/UFPel. E-mail: adgrutzma@ufpel.tche.br.

${ }^{5}$ Eng. Agr. Mestrando em Fruticultura de Clima Temperado - FAEM/UFPel. E-mail: lpicolotto@bol.com.br.

${ }^{6}$ Eng. Agr. Profissional liberal. E-mail: erkruger@bol.com.br.
} 
[Monilinia fructicola (Wint.) Honey] e a bacteriose [Xantomonas arboricola pv. Pruni (E. F. Smith)], nas regiões produtoras de pêssego no Sul do Brasil, é favorecida pelos fatores climáticos predominantes, caracterizados pela alta precipitação pluviométrica, acima de $1.500 \mathrm{~mm} /$ ano, alta umidade relativa do ar e incidência de ventos fortes durante a primavera e o verão, obrigando o produtor a intensificar o uso de insumos (Fachinello et al., 2002).

O presente trabalho objetivou comparar os sistemas de produção integrada (PI) e produção convencional (PC), quanto aos danos provocados por pragas (grafolita, mosca-das-frutas, gorgulho, cochonilha) e doenças (podridão-parda, bacteriose, sarna, outras doenças) e o número de aplicações de agrotóxicos, em cinco safras (1999-2003), na região de Pelotas-RS.

\section{MATERIALE MÉTODOS}

O experimento foi realizado em pomar comercial de pessegueiro, localizado em Pelotas-RS, no período de 1999 a 2003, e a idade das plantas variou de 7 a 11 anos no período. As plantas utilizadas foram da cultivar 'Diamante', enxertadas sobre o porta-enxerto Capdeboscq, conduzidas em sistema vaso e com espaçamento de $6,0 \times 4,0 \mathrm{~m}$. Para a condução nos diferentes sistemas de produção PI e PC, utilizaram-se duas áreas distanciadas $500 \mathrm{~m}$ e separadas por uma estrada, onde se determinaram 17 plantas, para constituírem cada parcela.

Foram realizadas análises visuais na colheita, identificando e registrando o número de frutos com danos causados pelas principais pragas e doenças do pessegueiro. As avaliações compreenderam: danos causados por pragas; ocorrência de doenças; danos mecânicos, e número de aplicações de agrotóxicos.

$\mathrm{Na} \mathrm{PC}$, foram adotados manejos e práticas culturais normalmente utilizadas pelo produtor, ou seja, tratamentos fitossanitários a calendário fixo, manejo do solo com grade na entrelinha de plantas, raleio leve, não-utilização de poda verde e ausência de monitoramento de pragas. Na PI, foram utilizadas as práticas de manejo definidas nas Normas Técnicas e Documentos de Acompanhamento da Produção Integrada de Pêssego (Fachinello et al., 2003), incluindo o cultivo mínimo do solo, uso de poda verde, monitoramento de pragas e doenças, recomendação de adubação baseada na análise foliar e do solo, cobertura verde na entrelinha, minimização do uso de agrotóxicos, atualização do produtor nas tecnologias da PIF e registro de todas as atividades executadas no pomar, na caderneta de campo, para permitir a rastreabilidade.

A adoção da caderneta de campo é obrigatória no sistema PI. Nesta, constam informações como: identificação dos talhões, monitoramento de pragas, registro da aplicação de agrotóxicos, aplicação de fertilizantes, além de manejo das plantas, como poda e raleio, permitindo a completa rastreabilidade da produção.

$\mathrm{Na}$ PI, a aplicação de agrotóxicos foi realizada de acordo com os critérios de incidência de pragas e doenças, baseada no monitoramento, no estádio fenológico da cultura, no histórico de fonte de inóculo e nas condições climáticas.

Para o monitoramento da grafolita (Grapholita molesta Busk), foram utilizadas armadilhas tipo delta, com atrativo sexual sintético, instaladas no mês de setembro, sendo que o nível de controle foi considerado quando a população atingiu 30 adultos/armadilha/semana, segundo recomendação das Normas PIP. Estas foram regularmente verificadas: contagem e limpeza semanais, mudança do piso a cada quatro semanas e troca do septo de feromônio a cada seis semanas.

Para mosca-das-frutas (Anastrepha fraterculus Wied), o monitoramento foi realizado através de atrativo alimentar (suco de laranja na concentração de 25\%), utilizando armadilhas McPhail, instaladas em outubro. Quando na contagem, verificou-se mais de uma mosca/ frasco/dia, e o controle foi realizado através da aplicação de isca tóxica (inseticida fosforado - malatiom + melaço) na borda do pomar.

A pulverização em área total somente foi adotada quando, nas armadilhas, foi capturada uma mosca, em média por semana, no período de inchamento dos frutos. A avaliação dos danos por gorgulho (Sitophilus zeamais Mots) foi realizada através de análise visual dos danos, na região peduncular dos frutos. A avaliação de cochonilhas foi realizada através de análise visual, localizando focos de infestação de coloração esbranquiçada nos ramos e tronco das plantas.

O manejo para controle das doenças podridão-parda [Monilinia fructicola (Wint.) Honey], sarna [Venturia inaequalis (Cooke)] e bacteriose [Xantomonas arboricola pv. Pruni (E. F. Smith)] foi realizado utilizando-se de fungicidas recomendados para a cultura do pessegueiro, respeitando os respectivos períodos de carência.

$\mathrm{O}$ delineamento experimental utilizado foi o inteiramente casualizado, com 17 repetições, sendo cada planta uma unidade experimental. Os dados foram submetidos à análise de variância e a comparação de médias pelo teste de Tukey $(a ́=0,05)$.

\section{RESULTADOS E DISCUSSÃ̃}

No período analisado (safras 1999-2003), os danos por grafolita foram de $1,11 \%$ e de $1,69 \%$, respectivamente, para os sistemas PI e PC (Tabela 1). De acordo com Fachinello et al. (2004), a adoção correta do monitoramento de pragas, para quantificar a incidência e os níveis de danos nos pomares, com a conseqüente redução no número de aplicações de agroquímicos e a utilização de produtos específicos e de menor impacto ambiental, promoveram um aumento populacional dos organismos benéficos nos pomares de pessegueiro.

A grafolita necessita de determinadas condições de umidade relativa, temperatura e ventos, para causar danos no pomar e, neste trabalho, observou-se maior incidência na última quinzena de dezembro. Na região da Serra Gaúcha, o ataque da grafolita inicia-se logo após a brotação do pessegueiro (final de agosto/início de setembro) nas cultivares precoces. São observados quatro períodos distintos de vôo dos adultos durante a estação produtiva do pessegueiro: meados de agosto, segunda quinzena de outubro, primeira semana de dezembro e primeira semana de janeiro (Botton et al., 2003).

Na região de Pelotas, os danos causados por mosca-das-frutas, não foram significativamente expressivos, em ambos os sistemas de produção. Isso foi decorrente do manejo preventivo, realizado pelo produtor nos pomares, incluindo o emprego de monitoramento com atrativo alimentar e aplicação de iscas tóxicas na borda do pomar, que permitiu a manutenção da população da praga em níveis toleráveis.

Quando o nível de pragas no pomar alcançou o nível de controle, os inseticidas utilizados pelo produtor para o controle foram Fenitrothion $\left(150 \mathrm{~mL} .100 \mathrm{~L}^{-1}\right)$ e Triclorfom $\left(300 \mathrm{~mL} .100 \mathrm{~L}^{-1}\right)$, principalmente para controle de grafolita e mosca-das-frutas, respectivamente.

Os danos decorrentes do ataque por gorgulho-do-milho foram em média de $2,12 \%$ na PI e $0,86 \%$ na PC (Tabela 1 ). Verificou-se, também, que o período de maior incidência da praga foi na segunda quinzena de dezembro. A maior incidência de danos por gorgulho, na área da PI, deve-se à maior proximidade do pomar às propriedades vicinais que produzem e armazenam milho, principal fonte de multiplicação da praga.

Gomes (2003) verificou alta intensidade de ataque de gorgulho na safra 2001-2002 na cultivar Chimarrita, com médias de 20,04 e 25,26\% nos sistemas PC e PI, respectivamente. Têm-se grandes dificuldades no controle do gorgulho, haja vista que este se abriga preferencialmente nas cachopas de frutas, reduzindo a eficiência das aplicações de agrotóxicos, sendo, portanto, imprescindível a realização do raleio, para melhorar a eficiência do controle químico (Gomes, 2003). Essa praga exige, também, um controle preventivo nos armazéns de milho, além de estudos e pesquisas visando a um controle mais eficiente no pomar.

A presença de cochonilhas não foi verificada na PI e, na PC, apresentou baixa incidência $(0,11 \%)$ (Tabela 1$)$. Essa praga possui ocorrência secundária no pessegueiro e, normalmente, aparece quando são efetuados tratamentos químicos, com inseticidas de amplo espectro, que ocasionam desequilíbrios no pomar.

A adoção do monitoramento de pragas pelo produtor demonstra ser uma alternativa confiável, para racionalizar a utilização 
TABELA 1 - Percentagem de frutos com danos, causados por pragas e doenças em pêssego na cultivar 'Diamante', produzidos em pomares conduzidos nos sistemas de produção integrada (PI) e convencional (PC), nas safras 1999 a 2003, FAEM-UFPel, Pelotas-RS, 2004.

\begin{tabular}{|c|c|c|c|c|c|c|c|c|c|c|c|c|}
\hline & \multicolumn{2}{|c|}{1999} & \multicolumn{2}{|c|}{2000} & \multicolumn{2}{|c|}{2001} & \multicolumn{2}{|c|}{2002} & \multicolumn{2}{|c|}{2003} & \multicolumn{2}{|c|}{ Média } \\
\hline Danos, pragas e doenças (\%) & PI & PC & PI & PC & PI & PC & PI & PC & PI & PC & PI & PC \\
\hline Grafolita & $0,95 \mathrm{a}^{*}$ & $1,04 \mathrm{a}$ & $0,34 b$ & $1,06 \mathrm{a}$ & $1,82 b$ & $4,45 \mathrm{a}$ & $1,46 a$ & $1,88 \mathrm{a}$ & $0,98 \mathrm{a}$ & $0,00 \mathrm{a}$ & 1,11 & 1,69 \\
\hline \multicolumn{13}{|l|}{$\mathrm{CV}(\%)=22,77$} \\
\hline Mosca-das-frutas & $0,06 \mathrm{a}$ & $0,44 \mathrm{a}$ & $0,00 \mathrm{a}$ & $0,00 \mathrm{a}$ & $0,18 \mathrm{a}$ & $0,00 \mathrm{a}$ & $0,01 \mathrm{a}$ & $0,00 \mathrm{a}$ & $0,66 \mathrm{a}$ & $0,29 a$ & 0,18 & 0,15 \\
\hline \multicolumn{13}{|l|}{$\mathrm{CV}(\%)=28,48$} \\
\hline Gorgulho & $1,18 \mathrm{a}$ & $1,12 \mathrm{a}$ & $2,45 \mathrm{a}$ & $0,93 b$ & $6,73 a$ & $2,16 b$ & $0,25 \mathrm{a}$ & $0,08 \mathrm{a}$ & - & - & 2,12 & 0,86 \\
\hline \multicolumn{13}{|l|}{$\mathrm{CV}(\%)=26,44$} \\
\hline Cochonilha & - & - & - & - & - & - & $0,00 \mathrm{a}$ & $0,44 a$ & - & - & 0,00 & 0,11 \\
\hline \multicolumn{13}{|l|}{$\mathrm{CV}(\%)=74,11$} \\
\hline Podridão-parda & $3,94 a$ & $1,64 b$ & $4,61 \mathrm{a}$ & $3,88 \mathrm{a}$ & $78,20 \mathrm{a}$ & $80,43 a$ & $39,36 \mathrm{~b}$ & $55,06 a$ & $5,25 b$ & $11,76 \mathrm{a}$ & 26,27 & $\begin{array}{l}30,5 \\
5\end{array}$ \\
\hline \multicolumn{13}{|l|}{$\mathrm{CV}(\%)=26,53$} \\
\hline Bacteriose & $4,03 b$ & $8,03 \mathrm{a}$ & $2,50 \mathrm{~b}$ & $4,09 \mathrm{a}$ & $3,65 \mathrm{a}$ & $2,25 \mathrm{a}$ & $0,07 \mathrm{~b}$ & $2,26 \mathrm{a}$ & - & - & 2,05 & 3,33 \\
\hline \multicolumn{13}{|l|}{$\mathrm{CV}(\%)=49,93$} \\
\hline Sarna & - & - & - & - & - & - & - & - & $0,00 \mathrm{~b}$ & $33,82 \mathrm{a}$ & 0,00 & 6,76 \\
\hline \multicolumn{13}{|l|}{$\mathrm{CV}(\%)=80,31$} \\
\hline Outras doenças (antracnose) & $0,38 \mathrm{a}$ & $0,52 \mathrm{a}$ & $1,14 \mathrm{a}$ & $0,67 \mathrm{a}$ & $1,26 \mathrm{~b}$ & $2,88 \mathrm{a}$ & $0,36 \mathrm{~b}$ & $3,67 \mathrm{a}$ & $0,66 \mathrm{a}$ & $1,47 \mathrm{a}$ & 0,76 & 1,84 \\
\hline
\end{tabular}

*Médias seguidas por letras distintas na linha referentes ao mesmo ano diferem significativamente entre si, pelo teste Tukey, em nível de 5\% de significância.

de agrotóxicos. Entretanto, constitui-se, ainda, um obstáculo a ser superado. Segundo Walker et al. (1998), para promover a expansão da PIF, é essencial a melhoria da confiabilidade, para a tomada de decisão e da simplicidade no entendimento do monitoramento pelos produtores.

No sistema PI, o percentual de frutas com podridão-parda foi de $26,27 \%$ e, na PC, foi de $30,55 \%$. Durante os anos com maior precipitação pluviométrica (2001 e 2002), ocorreram as maiores incidências da doença, sendo esta a maior causa das perdas nos pomares (Tabela 1). Esse resultado está de acordo com Farias et al. (2003), que verificaram ser a podridão-parda, responsável pelos maiores danos nas frutas, não havendo diferença significativa entre os sistemas PI e PC.

Com exceção das safras 1999 e 2000, a incidência de podridãoparda foi maior no sistema PC, evidenciando a importância da adoção de um programa de controle integrado de doenças, associando métodos culturais, químicos e tecnológicos, mantendo a população de patógenos em níveis aceitáveis. Além disso, a minimização na aplicação de agrotóxicos previne o surgimento de populações resistentes aos fungicidas, aumentando a vida útil dos produtos (Botton et al., 2000).

No ano de 2000, houve acúmulo de 586 horas de frio, com temperatura menor que $7,2^{\circ} \mathrm{C}$, e a precipitação pluviométrica média anual foi de $86,5 \mathrm{~mm}$. Já no ano de 2001, um ano atípico, no inverno, houve pouco acúmulo de frio (343 horas) e maior incidência de chuvas, com a média mensal de 174,1mm (Gomes, 2003). No período de colheita, mês de dezembro de 2001, registrou-se excesso de chuvas (200mm) e baixa insolação, fatores que propiciaram maior incidência de podridão-parda $(78,20 \%)$ para PI e $(80,43 \%)$ para PC.

Os danos por bacteriose também foram menores no sistema PI $(2,05 \%)$, comparados com PC (3,33\%) (Tabela 1$)$. Foi verificado que, nos primeiros anos de avaliação (1999-2000), os danos por bacteriose foram maiores em ambos os sistemas de produção. Posteriormente, com o crescimento das plantas de acácia-negra usadas como quebra-vento, diminuiu a incidência, destacando a importância da adoção de quebraventos na área produtiva, considerando-se que a penetração da bactéria ocorre através dos ferimentos, provocados pelos ventos fortes (Bleicher, 1997).

A ocorrência de sarna apresentou-se muito elevada no ano 2003, na PC, estando presente em 33,82\% dos frutos analisados (Tabela 1), em decorrência da alta concentração de inóculo e do excesso de sombreamento no pomar. Segundo Garrido \& Sônego (2003), a sarna ocorre com freqüência em regiões quentes e úmidas, e as medidas de controle que podem ser adotadas são: a poda verde e os tratamentos químicos.

Na classificação de outras doenças, apresentaram expressão a antracnose [Glomerella cingulata (Stoneman) Spauld. \& H. Schrenk] e a ferrugem [Tranzschelia discolor (Fuckel) Tranzschel \& Litv], sendo que, na média, foi menor na PI $(0,76 \%)$, comparado com PC $(1,84 \%)$ (Tabela 1). Verificou-se maior incidência de antracnose, no início do ciclo vegetativo, nos anos mais chuvosos e quentes. A ferrugem ocorre preferencialmente após a colheita, promovendo a queda antecipada das folhas, reduzindo, conseqüentemente, o acúmulo de reservas de carboidratos e comprometendo o próximo ciclo produtivo. Para minimizar tal problema, foi efetuada aplicação de fungicida (mancozeb - 200g.100L${ }^{1}$ ), após a colheita das frutas, nos dois sistemas de produção.

O número de tratamentos fitossanitários, nos dois primeiros anos, foi maior na PC (Tabela 2). Nos anos subseqüentes, a utilização de agrotóxicos foi minimizada nos dois sistemas, devido à incorporação de tecnologias preconizadas pela PIP. Entretanto, o manejo fitossanitário realizado na PC, diferencia-se da PI, pelos agrotóxicos utilizados e, em

TABELA 2 - Número de aplicações de agrotóxicos realizados em pêssegos 'Diamante' em pomares conduzidos nos sistemas de produção integrada (PI) e convencional (PC), nas safras 1999 a 2003, Pelotas-RS, 2004.

\begin{tabular}{|c|c|c|c|c|c|c|c|c|c|c|c|c|}
\hline & \multicolumn{6}{|c|}{ PI } & \multicolumn{6}{|c|}{ PC } \\
\hline & 1999 & 2000 & 2001 & 2002 & 2003 & Média/ano & 1999 & 2000 & 2001 & 2002 & 2003 & Média/ano \\
\hline Fungicidas & 7 & 7 & 6 & 8 & 7 & 7 & 8 & 7 & 7 & 8 & 7 & 7,4 \\
\hline Inseticidas & 0 & 0 & 2 & 2 & 2 & 1,2 & 2 & 2 & 2 & 2 & 2 & 2 \\
\hline Herbicidas & 1 & 1 & 1 & 1 & 1 & 1 & 2 & 2 & 1 & 1 & 1 & 1,4 \\
\hline
\end{tabular}


algumas situações, pelo uso de agroquímicos não registrados e/ou não permitidos, de acordo com as recomendações para a cultura.

$\mathrm{Na}$ produção integrada, a permissão para a utilização dos agrotóxicos é restritiva, de acordo com a toxicidade e o potencial residual. Desta forma, são permitidos somente os agrotóxicos mais eficientes e seletivos, reduzindo o risco de intoxicação do produtor e o impacto ambiental, além da produção de frutas com menor risco de contaminação.

Aproximadamente $70 \%$ das aplicações de agrotóxicos foram de fungicidas, em ambos os sistemas de cultivo, sendo que o controle da podridão-parda exigiu o maior número de aplicações. Quanto aos inseticidas, normalmente, realizou-se em cada safra uma aplicação para controle de grafolita no início da maturação dos frutos, e uma para controle de mosca-das-frutas na pré-colheita.

A redução do custo de produção pôde ser obtida com a PIP, através da minimização nas aplicações e dosagens de agrotóxicos. Em contrapartida, há um incremento no custo da mão-de-obra, armadilhas para monitoramento, calibração e regulagem de equipamentos. Além disso, os agrotóxicos seletivos recomendados pela PIP são, freqüentemente, mais caros que os inseticidas de amplo-espectro.

Mesmo assim, conforme demonstram os resultados obtidos por Vicenzi (2003), o custo de produção na PI foi 14,78\% superior à PC entretanto, a produtividade e a qualidade superior das frutas obtidas no sistema PI geraram um rendimento líquido 56\% superior. É necessário, portanto, considerar a preferência dos consumidores para a aquisição de alimentos que tenham a procedência e a qualidade asseguradas, o que pode ser obtido pela adoção de programas como a PI.

\section{CONCLUSÕES}

A análise dos resultados demonstra uma superação do sistema PI, quando comparado com o sistema PC, evidenciando que é possível conduzir os pomares de pessegueiro de acordo com as normas PIP, em relação ao ataque de pragas e doenças, número de aplicações de agrotóxicos, permitindo uma diminuição do impacto negativo do processo produtivo sobre o meio ambiente.

\section{REFERÊNCIAS}

ANDRIGUETO, J. R.; KOSOSKI, A. R. Marco legal da produção integrada de frutas do Brasil. Brasília: MAPA/SARC, 2002. 60p.

BLEICHER, J. Doenças de rosáceas de caroço (pessegueiro, ameixeira, nespereira, etc.). In: KIMATI, H.; AMORIM, L.; BERGAMIN FILHO, A.; CAMARGO, L. E. A.; REZENDE, J. A. M. Manual de fitopatologia: doenças das plantas cultivadas. 3. ed. São Paulo: Agronômica Ceres, 1997. v.2, p.621-627.

BOTTON, M.; ARIOLI, C. J.; BAVARESCO, A.; SCOZ, P. L. Sistema de produção de pêssego de mesa na região da Serra Gaúcha: principais pragas. Bento Gonçalves: Embrapa Uva e Vinho, 2003. (Sistema de Produção, 3). CD-ROM

BOTTON, M.; GARRIDO, L. da R.; GIRARDI, C. L.; HOFFMANN, A.; MELO, G. W. de.; BERNARDI, J.; SÔNEGO, O. R.; CZERMAINSKI, A. B. C.; DANIELI, R. Avaliação do sistema de produção integrada de pêssego de mesa na serra do RS - safra 1999-2000. In: SEMINÁRIO BRASILEIRO DE PRODUÇÃO INTEGRADA DE FRUTAS, 2., 2000, Bento Gonçalves. Anais ... Bento Gonçalves: Embrapa Uva e Vinho, 2000. p.64-67.
FACHINELLO, J.C.; TIBOLA, C.S.; MAY-DE MIO, L.L.; MONTEIRO, L.B. Produção integrada de pêssego (PIP). In: MONTEIRO, L.B.; MAY-DE MIO, L.L.; SERRAT, B.M.; MOTTA, A.C.; CUQUEL, F.L. Fruteiras de caroço: uma visão ecológica. Curitiba: UFPR, 2004.p. $363-390$.

FACHINELLO, J.C.; COUTINHO, E.F.; MARONDIN, G.A.B.; BOTTON, M.; MIO, D.; L.; M. Normas técnicas e documentos de acompanhamento da produção integrada de pêssego. Pelotas: Universidade Federal de Pelotas. Faculdade de Agronomia Eliseu Maciel, 2003.95p.

FACHINELLO, J.C.; TIBOLA, C.S.; VICENZI, M.; PARISOTTO, E.; PICOLOTTO, L.; MATTOS, M.L.T. Produção integrada de pêssegos: 3 anos de experiência na região de Pelotas-RS. In: CONGRESSO BRASILEIRO DE FRUTICULTURA, 17., 2002, Belém - PA. Anais... Belém: Sociedade Brasileira de Fruticultura, 2002. CD-ROM

FARIAS, R. de M.; NUNES, J. L.da S.; MARTINS, C. R.; GUERRA, D. S.; ZANINI, C.; MARODIN, G. A. B. Produção convencional x integrada em pessegueiro cv. Marli na depressão central do Rio Grande do Sul. Revista Brasileira de Fruticultura, Jaboticabal, v. 25, n. 2, p. $253-255,2003$

GARRIDO, L. da C.; SÔNEGO, O. R. Sistema de produção de pêssego de mesa na região da Serra Gaúcha - doenças fúngicas e bacterianas do pessegueiro. Bento Gonçalves: Embrapa Uva e Vinho, 2003. (Sistema de Produção, 3). CD-ROM

GOMES, F. R. C. Qualidade da fruta e do solo em pomares de pessegueiro manejados com aveia-preta. 2003. 84f. Tese (Doutorado em Agronomia - Fruticultura de Clima Temperado) - Faculdade de Agronomia Eliseu Maciel, Universidade Federal de Pelotas, Pelotas, 2003.

GONZALEZ-MORO, J. J. O. La trazabilidad y cultivos controlados e integrados. Santa Cruz de Tenerife: Jornada Autonómica de la Comunidad Canaria, 2002. Disponível em: <http:// www.libroblancoagricultura.com/libroblanco/jautonomica/canarias/ comunicaciones/oramas.pdf $>$. Acesso em: 18 jun. 2003.

INMETRO: Produzir com qualidade para gerar divisas. Disponível em: $<$ http://www.inmetro.gov.br>. Acesso em: 15 mar. 2004.

SANHUEZA, R. M. V. Outras estratégias de pesquisa e desenvolvimento na produção integrada de frutas. In: SEMINÁRIO BRASILEIRO DE PRODUÇÃO INTEGRADA DE FRUTAS, 2; 2000, Bento Gonçalves. Anais ... Bento Gonçalves: Embrapa Uva e Vinho, 2000. p. 60-63.

SANHUEZA, R. M. V.; ANDRIGUETO, J. R.; KOSOSKI, A. R. Situação atual da produção integrada de frutas no Brasil. In: SEMINÁRIO BRASILEIRO DE PRODUÇÃO INTEGRADA DE FRUTAS, 5; 2003, Bento Gonçalves. Anais ... Bento Gonçalves: Embrapa Uva e Vinho, 2003. p. 23-25.

VICENZI, M. Avaliação econômica de dois sistemas de produção de pêssego (Prunus persica L. Batsch): Convencional (PC) x Integrada (PI) no Município de Pelotas. 2003. 47f. Dissertação (Mestrado em Fruticultura de Clima Temperado) - Faculdade de Agronomia. Universidade Federal de Pelotas, Pelotas, 2003.

WALKER, J.T.S.; WEARING, C.H.; BRADLEY, S.J.; SHAW, P.W.; BURNIP, G.M.; TONKINS. A.R.; RICHARDSON, C.A.; HODSON, A. J. Integrated Fruit Production (IFP) for New Zealand PIPFRUIT: evaluation of pests management recomendations. In: PLANT PROTECTION CONFERENCE, 51., 1998, New Zealand. Proceedings... p.166-172. 